\title{
Biologia reprodutiva de Centrosema pubescens Benth. (Fabaceae) Centrosema pubescens Benth. (Fabaceae) reproductive biology
}

Resumo: A ecologia da polinização e o sistema reprodutivo de Centrosema pubescens Benth., uma espécie arbustiva, foram estudados numa floresta tropical do Acre. A antese é diurna e as flores são visitadas, basicamente, por abelhas (9 spp.) e vespas (5 spp.). A guilda de polinização é composta por abelhas dos gêneros Xylocopa, Bombus, Euglossa, Exarete, Mesoplia, Megachile e Trigona e por vespas das familias Polybinae e Scoliidae. Uma espécie de abelha e uma de mariposa apresentam comportamento de pilhadores de néctar. A espécie é autocompatível, mas produz frutos através de autofecundação e fecundação cruzada. Agentes polinizadores não são exigidos para a produção de frutos, uma vez que as flores têm apresentação secundária dos grãos de pólen.

Palavras-chave: Polinização. Vespas. Abelhas. Arbusto. Autocompatibilidade.

Abstract: The pollination ecology and breeding system of the shrubby species Centrosema pubescens Benth. Was studied in the on tropical forest of Acre. The anthesis is diurnal and the flowers were visited by bees ( 9 spp.) and wasps ( 5 spp.) basicaly. The guild of pollination is composed by bees of the genus Xylocopa, Bombus, Euglossa, Exarete, Mesoplia, Megachile and Trigona and by wasps of the of the families Polybinae and Scoliidae. One species of bee and of moth behave as nectar thieves. The species is self-compatible but ptoduce fruit via selfing and outcrossing. Pollen vectors are not required for fruit set because the flower shows secondary presentation of pollen's grain.

Keywords: Polination. Wasps. Bees. Shrubby. Reproductive system.

\footnotetext{
I Secretaria de Estado do Meio Ambiente. Cuiabá, Mato Grosso, Brasil (hnogueira@yahoo.com.br).
}

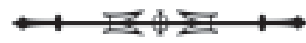




\section{INTRODUÇÃO}

O gênero Centrosema é americano e apresenta cerca de 50 espécies de arbustos ou ervas, prostrados ou escandentes (HUTCHINSON, 1964). O gênero pertence à família Fabaceae, considerada mais evoluída entre as Leguminosas (BARROSO et al., 1984; CRONQUIST, 1988).

Conforme Arroyo (1981), as Leguminosas de um modo geral (3 famílias), são polinizadas principalmente por abelhas, sendo que essa associação atinge um grau maior de especialização dentro de Fabaceae. Ainda segundo a autora, as flores de Centrosema são visitadas, principalmente, por abelhas grandes do gênero Xylocopa. As espécies de Fabaceae possuem flores elaboradas que resultam em sistemas particulares de polinização. Os visitantes das suas flores, para a obtenção do néctar, precisam pressionar as pétalas e expor os órgãos reprodutivos.

Neste trabalho são apresentados resultados sobre a biologia reprodutiva, incluindo dados sobre as características da antese, interações com visitantes e sobre o tipo de reprodução adotado por Centrosema pubescens Benth. em uma área de floresta tropical em regeneração no Acre.

\section{MATERIAL E MÉTODOS}

Os estudos foram conduzidos no Parque Zoobotânico (PZ) da Universidade Federal do Acre (UFAC). A UFAC está localizada dentro do perímetro urbano de Rio Branco, capital do Acre, tendo como coordenadas geográficas $9^{\circ} 58^{\prime} \mathrm{S}$, $67^{\circ} 48^{\prime} \mathrm{W}$ e altitude de $160 \mathrm{~m}$ (RADAMBRASIL, 1976). O campus da UFAC abrange 292 ha, sendo que cerca de 100 ha formam o PZ. Este situa-se a oeste do campus e tem como vegetação floresta de terra firme em diferentes estádios de regeneração. O município de Rio Branco apresenta clima do tipo Am (clima tropical úmido), segundo a classificação de Köppen (RADAMBRASIL, 1976). Na região podem ser observadas duas estações uma seca (maio a setembro) e outra chuvosa (outubro a abril) (DE DEUS et al., 1993).

As plantas acompanhadas são arbustos escandentes que crescem em locais abertos e ensolarados. Uma amostra do material botânico foi coletada e, após tratamento adequado, foi depositada no Herbário da UFAC.

\section{Morfologia e biologia floral}

Foram analisados quatro indivíduos quanto às características das inflorescências e das flores. Estas foram marcadas e acompanhadas por 25 dias entre 6 e 17 h. As inflorescências foram avaliadas quanto à posição no ramo e ao padrão de abertura dos botões. O número de inflorescência em cada ramo foi computado em 10 ramos. $\bigcirc$ número de flores por inflorescência foi determinado pela contagem de botões em 10 inflorescências por indivíduo $(\mathrm{N}=40)$. As estruturas florais foram medidas e descritas. Verificou-se o horário de abertura, o período de receptividade do estigma e de disponibilidade dos grãos de pólen, alteração de cor da corola, presença de odor e disposição dos elementos florais ao longo do dia. A receptividade do estigma foi avaliada em campo pela presença de exsudado e água oxigenada (ZEISLER, 1938). A viabilidade dos grãos de pólen foi determinada com azul de metileno em lactofenol (RADFORD et al., 1974). Para análise da viabilidade dos grãos de pólen foram coletados cinco botões em cada indivíduo, retiradas 10 anteras e esmagadas sobre lâmina com corante. Em cada lâmina foram contados os grãos de pólen em 10 campos, com microscópio ótico.

\section{Visitantes florais}

Os visitantes foram avaliados com relação ao horário de visita, número e comportamento dos indivíduos durante a visita e diversidade de espécies durante nove dias consecutivos. Insetos foram capturados e levados ao laboratório para a determinação do local de deposição do pólen. Os visitantes coletados

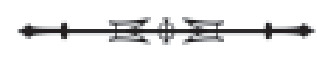


foram encaminhados para especialistas visando à sua identificação. Os insetos coletados foram depositados na coleção da UFAC, no Departamento de Agronomia.

\section{Fenologia reprodutiva}

Quatro indivíduos foram acompanhados durante a fenofase de florescimento. As observações foram realizadas, semanalmente, durante o período de florescimento da espécie. O florescimento foi definido como o período de tempo com emissão de botões e abertura de flores.

\section{Sistema reprodutivo}

Foram realizadas polinizações controladas com grãos de pólen coletados em flores recém-abertas. Os grãos coletados na mesma flor (autopolinização) e em flores de outros indivíduos (polinização cruzada). Um grupo de flores foi apenas ensacado para verificar a presença de autopolinização espontânea. Nas flores submetidas à polinização cruzada e para testes de agamospermia, os estames foram emasculados antes da abertura das anteras. Em cada tratamento, as flores foram polinizadas durante o período de receptividade do estigma e, posteriormente, ensacadas até o término dessa condição. A produção natural de frutos foi avaliada em flores apenas etiquetadas (controle). Os resultados foram considerados positivos com a formação de frutos contendo sementes normais.

\section{RESULTADOS}

O florescimento de Centrosema pubescens foi sincrônico intra e entre indivíduos. Os primeiros botões foram observados em maio, mas a abertura das flores ocorreu nos meses de junho e julho. Esse período do ano é caracterizado como meio da estação seca na região.

Os ramos reúnem, em média, 2 a 8 inflorescências $(N=10)$. As inflorescências são do tipo racemo que se abrem da base para o ápice, à medida que completam o seu desenvolvimento na axila das folhas. Cada inflorescência reúne, em média, 1,9 a 6 flores $(\mathrm{N}=28)$. As flores são hermafroditas, pentâmeras e com $3,5 \mathrm{~cm}$ de diâmetro. $\bigcirc$ cálice das flores é tubuloso, com dentes desiguais. A corola é lilás e reúne cinco pétalas. $\bigcirc$ estandarte apresenta guias de nectário, definidos por linhas amarelas e roxas que se estendem, longitudinalmente, até a base da pétala, que também é amarela. Das quatro outras pétalas que compõem a corola, duas, as alas, são livres entre si e duas são concrescidas em toda a sua extensão, formando a carena. A carena é côncava e recobre os órgãos reprodutivos. A flor é resupinada, o que coloca o estandarte como plataforma de pouso para os visitantes (Figura 1a). Nove dos dez estames são, parcialmente, concrescidos, formando um tubo, com apenas a porção superior dos filetes brancos livres (Figura 1 b). O décimo, isolado, é menor. As 10 anteras são introrsas, rimosas, amarelas e agrupam-se em torno do estigma. Os grãos de pólen são amarelos. $\bigcirc$ estilete e o estigma são brancos. O estigma é laminar, piloso na borda da lâmina e fica exposto na extremidade do tubo estaminal que, por sua vez, envolve todo o pistilo. Um nectário com forma de anel é verificado ao redor da base do ovário.

$\mathrm{Na}$ fase de botão, o estandarte recobre as alas, a carena e os órgãos reprodutivos. $\mathrm{Na}$ tarde do dia anterior à abertura da flor ocorre a deiscência das anteras, que envolvem o estigma. Em torno das $6 \mathrm{~h} 30$ da manhã seguinte, o estandarte está aberto e levemente curvado para o cálice. As demais pétalas estão com o ápice voltado em direção oposta ao estandarte. $\bigcirc$ tubo estaminal realiza movimento ascendente, permitindo que nove anteras se afastem do estigma, posicionando-se acima do mesmo. Apenas a antera do menor estame toca o estigma. Nessa fase as anteras estão, praticamente, vazias e secas e os grãos de pólen estão depositados sobre o estigma. A superfície estigmática está receptiva. Ainda nesse horário, pode-se observar o início da produção de néctar, que se acumula junto à base da corola. Em

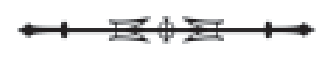


cada racemo são abertas uma ou, raramente, duas flores por dia. A receptividade do estigma foi verificada durante todo o dia de abertura da flor na superfície da lâmina, concentrada junto à borda.

A presença de grãos de pólen sobre o estigma pode ser observada entre 9 e $10 \mathrm{~h}$ da manhã, dependendo da intensidade de visitação dos insetos. As outras características são mantidas até em torno das 14 h, quando, então, o estandarte começa a se fechar. Aproximadamente às $17 \mathrm{~h}$, todas as flores estão com o estandarte fechado, recobrindo as demais pétalas (Figura 1c). No dia seguinte a corola está murcha e, assim como os órgãos reprodutivos, adquire uma coloração amarelada. A queda da corola é verificada no terceiro dia. $O$ néctar foi considerado o principal recurso oferecido pelas flores aos visitantes. Não foi detectada emissão de odor durante a vida da flor.

\section{VISITANTES}

As flores de C. pubescens são visitadas principalmente por abelhas e vespas (Tabela 1), que apresentam o mesmo comportamento: aproximam-se da flor, pousam diretamente sobre o estandarte, procurando coletar com a glossa o néctar acumulado na base da corola. Com o peso desses insetos, o estandarte voltase para baixo, assumindo a posição vertical. As demais pétalas são empurradas em direção oposta, provocando a exposição do tubo estaminal e do estigma para fora da carena. As vespas podem pousar sobre as outras pétalas e caminhar para o estandarte. Após a visita, quando as abelhas e vespas abandonam as flores, as pétalas voltam a encobrir os estames e estilete.

As maiores abelhas ( $=20 \mathrm{~mm}$ ), Bombus transversalis (Figura 1d), Exaerete smaragdina, Xylocopa (Neoxylocopa) colana e Xylocopa (Neoxylocopa) sp., agarram-se à base do estandarte com as pernas dianteiras e, enquanto coletam o néctar, recebem os grãos de pólen na cabeça. As abelhas menores $(=10 \mathrm{~mm})$ apoiam-se igualmente sobre $\mathrm{O}$ estandarte, ficando os grãos de pólen depositados sobre as asas (Euglossa sp.) ou sobre a cabeça (Megachile sp.).

Uma fêmea de Mesoplia sp. pousa próximo à base do estandarte e, após exposição dos órgãos sexuais, agarra-se com as pernas dianteiras ao tubo estaminal

Tabela 1. Relação dos visitantes de C. pubescens Benth. em uma área de floresta em regeneração no Acre Po-polinizador; Pi-pilhador.

\begin{tabular}{|c|c|c|c|c|}
\hline $\begin{array}{l}\text { GRUPO } \\
\text { POLINIZADOR }\end{array}$ & FAMÍLA / SUBFAMÍLA / TRIBO & $\begin{array}{l}\text { TAMANHO } \\
(\mathrm{mm})\end{array}$ & ESPÉCIE & $\mathrm{Po} / \mathrm{Pi}$ \\
\hline \multirow[t]{6}{*}{ ABELHAS } & $\begin{array}{l}\text { ANTHOPHORIDAE } \\
\text { Anthophorinae: Ericrocini } \\
\text { Xylocopinae: Xylocopini }\end{array}$ & $\begin{array}{l}\leq 10 \\
\geq 20 \\
\geq 20\end{array}$ & $\begin{array}{l}\text { Mesoplia sp. } \\
\text { Xylocopa (Neoxylocopa) colana } \\
\text { Xylocopa (Neoxylocopa)sp. }\end{array}$ & $\begin{array}{l}\text { Po } \\
\text { Po } \\
\text { Po }\end{array}$ \\
\hline & APIDAE & & & \\
\hline & $\begin{array}{l}\text { Bombinae: Bombini } \\
\text { Bombinae: Euglossini }\end{array}$ & $\begin{array}{l}\geq 20 \\
\leq 10 \\
\leq 10\end{array}$ & $\begin{array}{l}\text { Bombus transversalis } \\
\text { Euglossa sp. } \\
\text { Exaerete smaragdina Buérin. }\end{array}$ & \\
\hline & Meliponini: Trigonina & $\leq 10$ & Trigona (Trigona) sp. & $\mathrm{Po} / \mathrm{Pi}$ \\
\hline & $\begin{array}{l}\text { MEGACHILIDAE } \\
\text { Megachilinae: Megachilini }\end{array}$ & $\leq 10$ & Megachile sp. & Po \\
\hline & OXAEIDAE & $\geq 20$ & Oxaea laeta & $\mathrm{Pi}$ \\
\hline \multirow[t]{2}{*}{ VESPAS } & POLYBINAE & $\geq 20$ & sp. & $\mathrm{Pi}$ \\
\hline & SCOLIIDAE & $\geq 20$ & sp1, sp2, sp3 e sp4 & Po \\
\hline MARIPOSAS & HESPERIDAE & - & sp1 & $\mathrm{Pi}$ \\
\hline
\end{tabular}

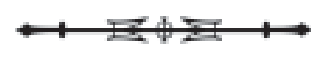


e vibra as anteras. Durante esse movimento, tocam o estigma. Nessa espécie os grãos de pólen ficam depositados na porção ventral do abdome. As vespas que visitam as flores de $C$. pubescens são grandes e pilosas (=20 mm), fêmeas de Scoliidae (sp1, sp2, sp3 e sp4) (Figuras 1e e 1f), sendo que os grãos de pólen aderem na região dorsal do corpo.

Para um grupo de visitantes, Oxaea laeta, Trigona sp., Polybinae (sp1) e Hesperidae (sp1), o acesso ao néctar é obtido após o pouso sobre as alas e carena e posterior introdução da glossa ou probóscide entre estas pétalas e o estandarte. Esses visitantes nunca chegam a contatar os órgãos sexuais, exceto Trigona sp., quando corta a porção superior das alas e da carena, e, também, as anteras, para ter acesso aos grãos de pólen. Quando cortam as pétalas, essas abelhas tocam o estigma e coletam grãos de pólen por até dois minutos na flor. Realizam de três a quatro visitas consecutivas à mesma flor.

As abelhas e vespas efetuam visitas durante toda a manhã, atingindo o seu pico de atividade entre $8 \mathrm{~h}$ e $10 \mathrm{~h}$. As abelhas permanecem cerca de 5 a $15 \mathrm{~s}$ por flor. As visitas das vespas são mais longas, cerca de 15 a 50 s por flor. As abelhas visitam com maior freqüência as flores de C. pubescens. Das 86 visitas às flores registradas, 65 (75,6\%) foram realizadas por abelhas.
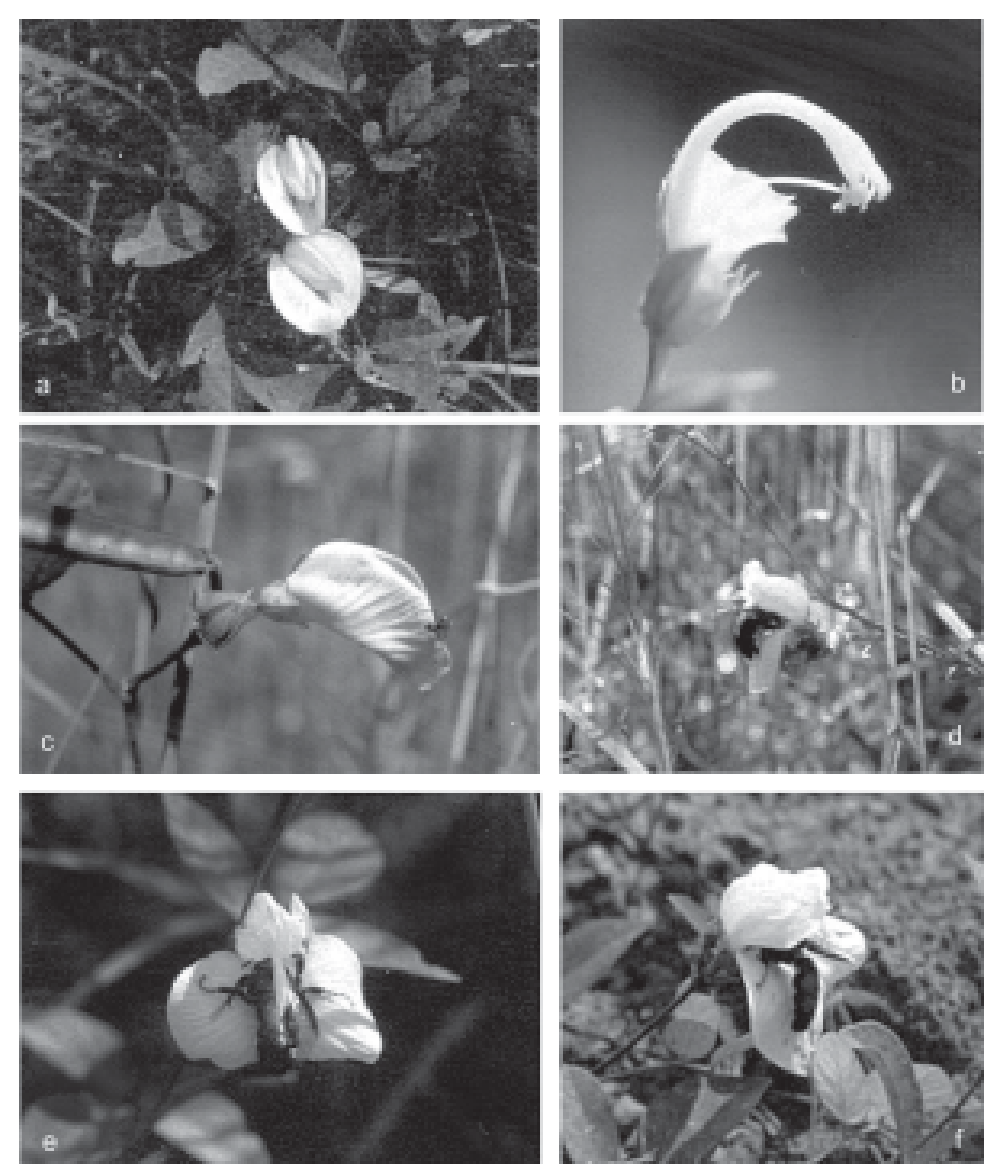

Figura 1. C. pubescens Benth.; a) flores; b) detalhe sobre a disposição do tubo estaminal; c) flor velha, com estandarte envolvendo os órgãos reprodutivos; d) visitante: Bombus transversalis; e) f) visitantes: espécies de Scoliidae (Fotos: H. B. Nogueira Borges).

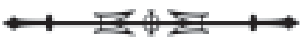




\section{Sistema reprodutivo}

Os indivíduos apresentam sistema reprodutivo caracterizado por autocompatibilidade (Tabela 2). Índice significativo de aborto, acima de $60 \%$, foi constatado nas flores avaliadas quanto à autopolinização manual e fecundação cruzada. O percentual de frutos formados como resultado de autopolinização espontânea foi significativamente superior aos produzidos após fecundação cruzada $\left(X^{2}=8,47, P<0,05\right)$ e após autopolinização manual $\left(X^{2}=10,91, P<0,05\right)$, mas não diferiu, significativamente, da observada na polinização natural $\left(X^{2}=1,61, P>0,05\right)$. $A$ percentagem de frutos produzidos com autopolinização manual foi semelhante à de fecundação cruzada $\left(X^{2}=0,167, P>0,05\right)$. Em todos os tratamentos foi observada variação entre os indivíduos quanto à produção de frutos. A espécie não apresenta agamospermia nos indivíduos testados. Os grãos de pólen exibiram alta viabilidade (Tabela 2).

\section{DISCUSSÃO E CONCLUSÕES}

Os indivíduos de C. pubescens floresceram, sincronicamente, durante dois meses na estação seca. Florescimento, nesse período do ano, é comum em outras florestas tropicais. Opler, Frankie e Baker (1980), estudando arvoretas e arbustos em áreas de floresta tropical úmida e outras secas, observaram produção de flores em diferentes espécies durante todo o ano, mas com maior número de taxa em atividade reprodutiva durante os meses mais secos.
O florescimento observado durante dois meses nos indivíduos de C. pubescens implica em disponibilidade por um longo período de tempo de recursos para os muitos insetos que visitam as suas flores. São 15 espécies de animais que procuram as flores dessa espécie em busca, principalmente, de néctar. Apenas duas espécies de abelhas buscam, também, grãos de pólen - Mesoplia sp. e Trigona sp. A maior parte dos visitantes atua como polinizador das flores. São nove espécies de abelhas e quatro de vespas, representando 80\% (12/15) do total. Esse resultado está de acordo com a tendência observada entre plantas de apresentar sistemas de polinização generalistas. Nesse caso a polinização é desenvolvida por grupos particulares de insetos e não por determinada espécie (WASER et al., 1996).

Contudo, vale destacar que as abelhas, em função do número de espécies e de visitas realizadas às flores, são os principais polinizadores de C. pubescens. As abelhas são consideradas os agentes polinizadores mais importantes em vegetação tropical, em função do número e diversidade de plantas polinizadas (BAWA, 1990; KRESS; BEACH, 1994).

Uma espécie de abelha (Oxaea laeta), uma de vespa (Polybinae) e outra de mariposa (Hesperidae) são pilhadoras de néctar, uma vez que nunca chegam a tocar os órgãos reprodutivos das flores de C. pubescens. É comum a presença de espécies de Oxaea pilhando flores em busca de néctar. Roubik (1989) comenta que espécies de Oxaea são pilhadoras comuns nas flores de espécies de

Tabela 2. Resultados dos experimentos de sistema reprodutivo e viabilidade do pólen em quatro plantas de C. pubescens Benth.

\begin{tabular}{|c|c|c|c|c|c|}
\hline Indivíduos & $\begin{array}{c}\text { Autopolinização } \\
\text { manual } \\
\%(\mathrm{Fl} / \mathrm{Fr})\end{array}$ & $\begin{array}{c}\text { Autopolinização } \\
\text { espontânea } \\
\text { \% (Fl/Fr) }\end{array}$ & $\begin{array}{c}\text { Polinização } \\
\text { Cruzada } \\
\%(\mathrm{Fl} / \mathrm{Fr})\end{array}$ & $\begin{array}{c}\text { Agamospermia } \\
\%(\mathrm{Fl} / \mathrm{Fr})\end{array}$ & $\begin{array}{l}\text { Viabilidade } \\
\text { do pólen } \\
\% \text { (Gf/Gt) }\end{array}$ \\
\hline 1 & $8,3(12 / 1)$ & $6,2(16 / 1)$ & $0(26 / 0)$ & $0(15 / 0)$ & - \\
\hline 2 & $0(30 / 0)$ & $20(50 / 10)$ & $50(30 / 15)$ & $0(15 / 0)$ & $96,4(2200 / 2281)$ \\
\hline 3 & $37,5(24 / 9)$ & $90(20 / 18)$ & - & $0(10 / 0)$ & $96(3695 / 3848)$ \\
\hline 4 & - & - & $0(12 / 0)$ & $0(10 / 0)$ & $95,8(4823 / 5032)$ \\
\hline Total & $15(66 / 10)$ & $33,7(86 / 29)$ & $17(68 / 15)$ & $0(50 / 0)$ & \\
\hline
\end{tabular}

Fl-número de flores; Fr-número de frutos; Gf-número de grãos de pólen férteis; Gt-número total de grãos de pólen.

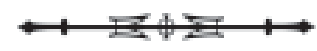


Bignoniaceae. Indivíduos de Trigona sp. podem atuar como pilhadores ou como polinizadores das flores de C. pubescens, o que depende do fato de conseguirem expor ou não os órgãos reprodutivos.

Em C. pubescens, além de Xylocopa, outros gêneros de abelhas reúnem espécies consideradas polinizadoras. São abelhas que se ajustam ao sistema particular de polinização da espécie. Além das abelhas, também espécies de vespas atuam como polinizadoras das flores de C. pubescens. Esse grupo de insetos poliniza igualmente as flores de outras espécies de Fabaceae, como Vignia minima (GOPINANATHAN; BABU, 1987) e Stylosanthes spp. (PEREIRA-NORONHA; SILBERBAUERGOTTSBERGER; GOTTSBERGER, 1982), que apresentam o mesmo sistema de polinização.

A polinização das flores de C. pubescens é desenvolvida através de mecanismo particular de exposição dos órgãos reprodutivos. O tubo estaminal, o estilete e o estigma são liberados para fora da carena com a pressão provocada pelo peso do visitante que pousa sobre o estandarte. Segundo Arroyo (1981), esse mecanismo chamado de tripping é próprio de muitos gêneros de Fabaceae. De acordo com a autora, nas flores resupinadas de Centrosema o estandarte atua como plataforma de pouso para os visitantes e a carena tem como função proteger o tubo estaminal. Como exemplos de espécies de Fabaceae com esse mecanismo de polinização é possível citar: Vigna vexillata (L.) A. Rich. (HEDSTRÖM; THULIM, 1986), V. longifolia (Benth.) Verdcourt (HOC et al., 1993) e Macroptilium bracteatum (Nees \& Mart.) Maréchal e Baudet (BRIZUELA et al., 1993).

Conforme Arroyo (1981), estudos dentro de Fabaceae indicam que o mecanismo de tripping apresenta variação, resultando em três tipos de apresentação dos órgãos reprodutivos: mecanismo valvular; mecanismo de bombeamento (pump); e mecanismo de escova do estilete (brush). No caso de C. pubescens pode ser observado o mecanismo de bombeamento, onde a coluna estaminal é liberada através de uma abertura no ápice da carena. Pereira-Noronha, Silberbauer-gottsberger e Gottsberger (1982) chamam o mecanismo de bombeamento de mecanismo de 'êmbolo' ou 'pistão'. Os autores descrevem esse mecanismo para três espécies de Stylosanthes e citam a presença do mesmo em nove outros gêneros de Fabaceae.

Uma outra particularidade observada no sistema de polinização de C. pubescens é a deposição dos grãos de pólen sobre o estigma. A transferência dos grãos de pólen das anteras para outras estruturas florais é indicada como 'apresentação secundária dos grãos de pólen' e é considerada uma adaptação das flores à polinização (HOWELL; SATZER; KNOX, 1993). A apresentação secundária dos grãos de pólen sobre o estigma favorece a autofecundação na espécie. A presença de polinizadores teria como função a transferência de grãos entre plantas, garantindo a fecundação cruzada das flores.

Autocompatibilidade aparece de forma significativa nas flores de $C$. pubescens. A ausência de diferenças significativas entre autopolinização espontânea e a polinização natural sugere que a manipulação inadequada das flores, durante autopolinização manual e fecundação cruzada, deve ser o principal fator responsável pela queda de boa parte das flores nesses tratamentos. A alta viabilidade dos grãos de pólen e freqüência dos visitantes descartam hipóteses de aborto relacionadas com esterilidade e polinização inadequada na formação de frutos. Em função da não-formação de frutos após emasculações das flores, a agamospermia é descartada na espécie. A alta viabilidade dos grãos de pólen e a ausência de agamospermia complementam a idéia de reprodução sexuada bem sucedida na espécie.

A autocompatibilidade é, aparentemente, freqüente nas espécies de Centrosema. Arroyo (1981) relata que estudos envolvendo 13 espécies desse gênero revelaram a presença de autocompatibilidade em

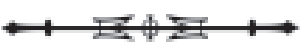


todos os taxa. A autora afirma que, em princípio, auto-incompatibilidade é menos comum em Fabaceae que em Caesalpiniaceae e Mimosaceae.

A espécie pode ser caracterizada como autógama, em cujas flores pode ocorrer a autofecundação dos óvulos sem a necessidade de polinizadores, uma vez que foi verificada deposição dos grãos de pólen sobre o estigma sem o auxilio de insetos. Entretanto, apesar de autocompatível, ocorre a fecundação cruzada na espécie, representando uma garantia de manutenção da variabilidade genética que é necessária para se manter no ambiente diante de pressões ambientais tão comuns em áreas tropicais.

\section{AGRADECIMENTOS}

Agradeço ao Dr. Elder F. Morato (UFAC) e Dr. João M. F. de Camargo, da Universidade de São Paulo (USP-Ribeirão Preto), pela identificação das abelhas e vespas e à UFAC por permitir o desenvolvimento do trabalho no Parque Zoobotânico. $\bigcirc$ apoio financeiro para esse trabalho foi dado pelo Conselho Nacional de Desenvolvimento Científico e Tecnológico (CNPq), através de uma bolsa de Desenvolvimento Científico Regional (Processo 300929/91-NV).

\section{REFERÊNCIAS}

ARROYO, M. T. K. 1981. Breeding systems and pollination biology in Leguminosae. In: POLHILL, R. M.; RAVEN, P. H. (Ed.). Advances in legume systematics. Kew: Royal Botanic Gardens. p. 723-769. BARROSO, G. M. et al. 1984. Sistematica de angiospermas do Brasil. Viçosa: Imprensa Universitária da UFV. p. 15-90. v. 2. BAWA, K. S. 1990. Plant-pollinator interactions in topical rain forests. Ann. Rev. Ecol. Syst., v. 21, p. 399-422.
BRIZUELA, M. M. et al. 1993. Biologia floral de Macroptilium bracteatum (Leguminosae, Phaseolae). Darwin., v. 32, n. 1-4, p. 41-57.

CRONQUIST, A. 1988. The evolution and classification of flowering plants. New York: The New York Botanical Garden. 555 p. DE DEUS, C. E. et al. 1993. Comportamento de 28 espécies arbóreas tropicais sob diferentes regimes de luz em Rio Branco, Acre. Rio Branco: Gráfica Universitária - UFAC. 170 p. GOPINATHAN, M. C.; BABU, C. R. 1987. Breeding systems and pollination in Vignia minima (Leguminosae, Papilionoideae). Pl. Syst. Evol., v. 156, p. 117-126.

HEDSTRÖM, I.; THULIN, M. 1986. Pollination by hugging mechanism in Vigna vexillata (Leguminosae-Papilionoideae). Pl. Syst. Evol., v. 154, p. 275-283.

HOC, P. S. et al. 1993. Biologia floral de Vigna longiflora (leguminosae, Phaseolae). Darwin., v. 32, n. 1-4, p. 27-39.

HOWELL, G. J.; SATEER, A. T.; KNOX, R. B. 1993. Secondary pollen presentation in angiosperms ans its biological significance. Aust. J. Bot., v. 41, p. 417-438.

HUTCHINSON, J. 1964. The genera of flowering plants. Oxford: Claredon Press. 516 p. v. 1

KRESS, W. J.; BEACH, J. H. 1994. Flowering plant reproductive systems. In: MC DADE, L. A. et al. (Ed.). La Selva: ecology and natural history of a neotropical rain forest. Chicago: The University of Chicago Press. p. 161-182.

OPLER, P. A.; FRANKIE, G. W.; BAKER, H. G. 1980. Comparative phenological studies of treelet and srub species in tropical wet and dry forests in the lowlands of Costa Rica. J. Ecol., v. 68, p. 167-188. PEREIRA-NORONHA, M. R.; SILBERBAUER-GOTTSBERGER, I.; GOTTSBERGER, G. 1982. Biologia floral de Stylosanthes (Fabaceae) no cerrado de Botucatu, estado de São Paulo. Rev. Bras. Biol., v. 42, n. 3 , p. $595-605$

RADAMBRASIL. 1976. Levantamento de recursos naturais: geologia, geomorfologia, pedologia, vegetação e uso potencial da terra. Rio de Janeiro: Ministério das Minas e Energia, Departamento Nacional da Produção Mineral. 464 p. v. 12.

RADFORD, A. E. et al. 1974. Vascular plant systematics. New York: New York Harper \& How Publishers. p. 211-236.

ROUBICK, D. W. 1989. The ecology and natural history of tropical bees. Cambridge: Cambridge University Press. 514 p. WASER, N. M. et al. 1996. Generalization in pollination systems, and why it matters. Ecol., v. 77, n. 4, p. 1043-1060.

ZEISLER, M. 1938. Über die abgrenzung der igentlichen narbenfläche mit hilf von reaktionen. Beih. Bot Zentralbl., v. 58a, p. 308-318. 